\title{
Effect of thermal ageing on the mechanical properties and cracking behaviour of asphalt concrete
}

\author{
B. KOUEVIDJIN ${ }^{1,2}$, J-F. BARTHELEMY ${ }^{1}$, C. SOME ${ }^{1}$, H. BEN DHIA ${ }^{2}$, A. FEESER ${ }^{3}$ \\ ${ }^{1}$ Cerema, Project-Team DIMA, 77171 Sourdun, France \\ ${ }^{2}$ Paris-Saclay University, CentraleSupelec, MSSMat Laboratory, 91191 Gif-sur-Yvette \\ ${ }^{3}$ Cerema, Laboratory of Strasbourg, 67000 Strasbourg, France
}

\begin{abstract}
:
This article assesses the impact of ageing on the properties of asphalt concrete (AC) by combining experiments and numerical simulations. Rheological tests were performed at four thermal ageing duration ( $0,3,6$ and 9 days). The results show an increase in the complex modulus and a decrease in phase angle with ageing time. For each ageing time, semi-circular bending tests were carried out under two loading rates $(1 . \mathrm{mm} / \mathrm{min}$ and $5 . \mathrm{mm} / \mathrm{min})$ and three temperatures $\left(-20^{\circ} \mathrm{C}, 0^{\circ} \mathrm{C}\right.$ and $\left.20^{\circ} \mathrm{C}\right)$. The results shown an increase of the peak load when the loading rate increases for each thermal ageing time and temperature. No meaningful variation of the peak load with respect to the ageing time was observed at low temperatures. However, it was found that at $20^{\circ} \mathrm{C}$, the peak load increases with ageing duration. A finite element modelling was implemented to simulate the force-deflexion curve, coupling viscoelastic behaviour and crack growth criterion. The results show a similarity between numerical and experimental results.
\end{abstract}

Keywords: asphalt concrete, viscoelasticity, crack growth, thermal ageing.

\section{Introduction}

Cracking which represents one the main forms of pavement pathologies, is often accelerated by the thermal ageing phenomenon of AC. A better understanding of the effect of thermal ageing on the rheological and fracture properties of $\mathrm{AC}$ is then a necessary step in predicting the service life of pavement structures. Significant research have been conducted to investigate the mechanical and chemical aspects of AC thermal ageing [1, 2]. However, few studies deal with the impact the impact of thermal ageing on cracking properties under different loading rates and different temperatures.

On the numerical level, models of fracture mechanics have been developed by several authors. Most of them have been applied to AC while describing them as elastic materials. Theoretical analyses of viscoelastic fracture mechanics and their applications to viscoelastic materials such as AC are quite limited. Continuum damage models such as cohesive zone model[3] are often used to model the crack growth in AC. These models are simple to implement but very sensitive to the mesh size. Schapery et al.[4] have developed numerical methods to determine the mechanical fields at the crack tip and the 
energy release rate in the crack propagation process over time. S.T. Nguyen et al.[5] studied crack growth in viscoelastic materials using an energetic approach by adopting a direct calculation procedure for the energy release rate.

The effect of loading rate, thermal ageing and temperature on viscoelastic crack growth are the issues addressed in this paper.

In the next section, rheological and cracking tests of AC subjected to thermal ageing are presented. Section 3 describes an overall energetic approach to study the crack growth in $\mathrm{AC}$ based on the energetic criterion described in [5]. In section 4, computational and experimental cracks growth were compared in order to verify the accuracy of the numerical models at different ageing time and loading rate.

\section{Rheological and crack growth properties of asphalt concrete}

\subsection{Materials and method}

The asphalt mix formula used in this study is a semi-coarse asphalt concrete (AC 10). The bitumen used is a conventional paving grade bitumen, with a measured penetrability of $42 \times 0.1 \mathrm{~mm}$ and a softening temperature of $53.2^{\circ} \mathrm{C}$.

\section{Laboratory ageing procedure and specimen preparation}

In order to replicate in the laboratory the ageing of $\mathrm{AC}$ over the life of the pavements, the RILEM method reported in CEN/TS $12697-52$ is adopted. In this ageing procedure, the mix is manufactured and the loose mixture is spread in thin layer $(25 \mathrm{~mm})$ into pans. Once the mixture is cooled down to $135^{\circ} \mathrm{C}$, the pans are placed into oven for $8 \pm 0.5 \mathrm{~h}$. Then, the mixture is cooled to $85^{\circ} \mathrm{C}$ and maintained at this temperature for 3 long-term ageing durations (3,6,9 days). The unaged and aged (referenced respectively by t0,t3,t6 and t9) cylindrical and plates specimens have been compacted and then sliced to obtain semi-circular and prismatic samples. On each of these specimens,

\section{Complex modulus test}

The complex modulus test was carried out on prismatic specimens using the two-point bending method described in NF EN 12697-26. The tests were performed in the linear viscoelastic range at five frequencies ( 3 to $40 \mathrm{~Hz}$ ) and nine temperatures $\left(-30\right.$ to $50^{\circ} \mathrm{C}$ ).

\section{Semi-circular bending (SCB) test}

For each thermal ageing time, SCB test was conducted at three temperatures $\left(-20^{\circ} \mathrm{C}, 0^{\circ} \mathrm{C}\right.$ and $20^{\circ} \mathrm{C}$ ) and two loading rates $(1$ and $5 \mathrm{~mm} / \mathrm{min})$. More details about the test, please refer to NF EN 12697-44.

\subsection{Experimental results and discussion}

\section{Rheological analysis}


The variations in rheological properties due to ageing were examined in this paragraph. The results shown in Fig. 1a and $1 \mathrm{~b}$ indicate an increase in the complex modulus and a decrease in the phase angle between 0 days and 9 days of ageing. Indeed, viscoelastic properties are more affected by thermal ageing at very low frequencies. The full line curves on the figures Fig. 1a and $1 \mathrm{~b}$ illustrate the calibration of the Generalised Maxwell (GM) model with 18 elements for a reference temperature $\theta_{R}=0^{\circ} \mathrm{C}$. For this number of elements, the results of complex modulus and phase angle given by the model are nearly the same as the experimental results.

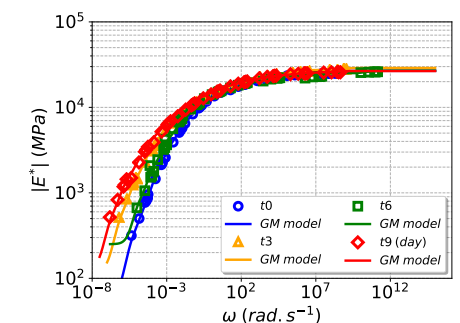

(a)

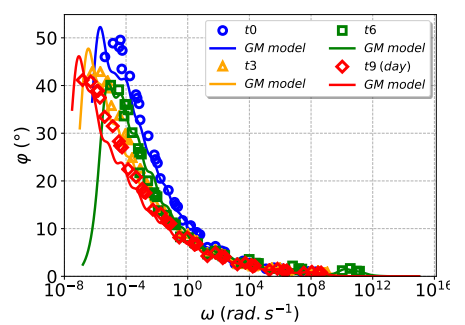

(b)

Fig. 1. Master curves of : (a) $\left|E^{*}\right|$ at $\theta_{R}=0^{\circ} \mathrm{C}$; (b) $\varphi$ at $\theta_{R}=0^{\circ} \mathrm{C}$

\section{Fracture analysis}

Fig. $2 \mathrm{a}$ and $2 \mathrm{~b}$ shown a slight increase of the peak load when the loading rate increases. However, no significant variation of the peak load with respect to ageing times was observed at these temperatures. The results obtained at $20^{\circ} \mathrm{C}$ (Fig. 2c) indicated a significant increase in peak load when the loading rate increases. In contrast to the results obtained at $-20^{\circ} \mathrm{C}$ and $0^{\circ} \mathrm{C}$, an increase of peak load was observed at $20^{\circ} \mathrm{C}$ when the ageing time increases. Finally, it can been seen that, for each ageing time, the peak load decreases with increasing temperature due to the material's viscoelasticity. Fig. 3a ,3b and $3 c$ shown a decrease in fracture strain (Eq. (1)) as a function of ageing time, due to the hardening of the material.

$$
\varepsilon_{\max }=\frac{U_{F_{\max }}}{W} \times 100
$$

Where $U_{F_{\max }}$ is the displacement at the peak load and $W$ the height of the specimen.

\section{Viscoelastic crack growth modelling}

In this section, the energetic approach to crack propagation in mode I in a viscoelastic medium is presented [5]. Let's consider a pre-cracked domain $\Omega(l)$ (see Fig. 4a) . For clarity's sake, a progressive kinematic loading $\xi(t)$ is defined whose dual is noted $\mathcal{Q}(t)$. In the case of an isothermal and uniform transformation, the Clausius-Duhem's inequality can be written as:

$$
D=\mathcal{Q} \dot{\xi}-\dot{\mathcal{W}} \geqslant 0
$$




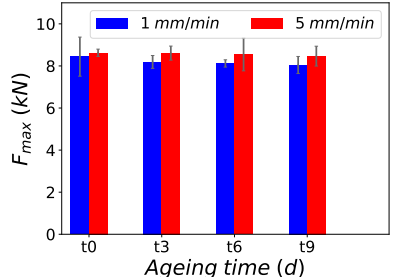

(a)

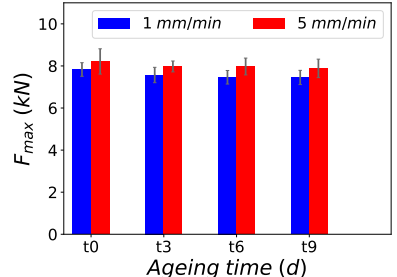

(b)

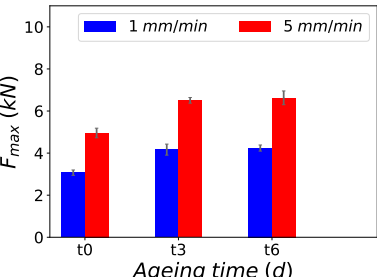

(c)

Fig. 2.Effect of ageing and loading rate on peak load at : (a) $-20^{\circ} \mathrm{C}$; (b) $0^{\circ} \mathrm{C}$; (c) $20^{\circ} \mathrm{C}$

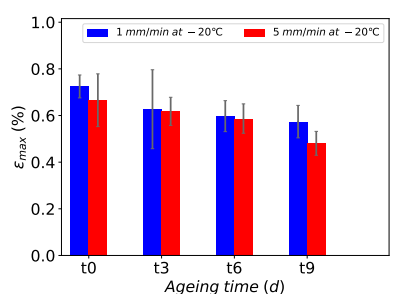

(a)

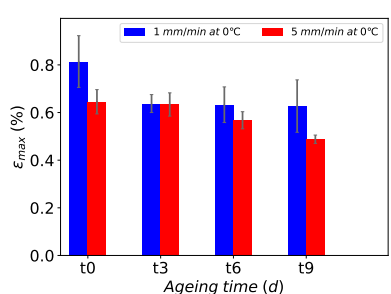

(b)

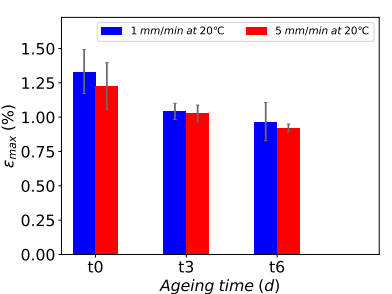

(c)

Fig. 3.Effect of ageing and loading rate on fracture strain at :(a) $-20^{\circ} \mathrm{C}$; (b) $0^{\circ} \mathrm{C}$; (c) $20^{\circ} \mathrm{C}$

Where $\mathcal{W}$ denotes the elastic strain energy stored in the system. The viscoelastic behaviour is modelled by the GM model shown in Fig. 4b. This behaviour can be formulated as follows:

$$
\underline{\underline{\boldsymbol{\sigma}}}(t)={\underset{\sim}{\mathbb{C}}}^{e l}: \underline{\underline{\varepsilon}}(t)-\underline{\underline{\boldsymbol{\sigma}}}^{r}(t) \quad \text { avec } \quad \stackrel{\sim}{\sim}^{e l}=\sum_{i=0}^{r} \underset{\sim i}{\mathbb{C}} \quad \text { et } \quad \underline{\underline{\boldsymbol{\sigma}}}^{r}(t)=\sum_{i=1}^{r} \underset{\sim i}{\mathbb{C}}: \underline{\underline{\varepsilon}}_{i}^{\vartheta}(t)
$$

Where $\underline{\varepsilon}_{i}^{\vartheta}, \underset{\sim}{\mathbb{C}}$ are respectively the viscous strain and elasticity tensor of Maxwell's i-th element. ${\underline{\underline{\sigma^{r}}}}^{i}$ can be interpreted as pre-stress tensor. From Eq. (3), it can be shown that the elastic strain energy does not depends only on the load $(\xi)$ and the geometry $(l)$ but also on the field of internal variables $\left\{\underline{\underline{\varepsilon}}_{i}^{\vartheta}, i=1, r\right\}$ :

$$
\mathcal{W}\left(\xi, l,\left\{\underline{\underline{\varepsilon}}^{\vartheta}\right\}\right)=\frac{1}{2} \int_{\Omega(l)}\left[\underline{\underline{\varepsilon}}: \underset{\sim 0}{\mathbb{C}}: \underline{\underline{\varepsilon}}+\sum_{i=1}^{r}\left(\underline{\underline{\varepsilon}}-\underline{\underline{\varepsilon}}_{i}^{\vartheta}\right): \underset{\sim i}{\mathbb{C}}:\left(\underline{\underline{\varepsilon}}-\underline{\underline{\varepsilon}}_{i}^{\vartheta}\right)\right] \mathrm{d} \Omega(l)
$$

Introducing Eq. (4) into Eq. (2) and assuming that the dissipation related to the evolution of the crack is proportional to the length rate of the crack, the crack growth criterion can be formulated as follows:

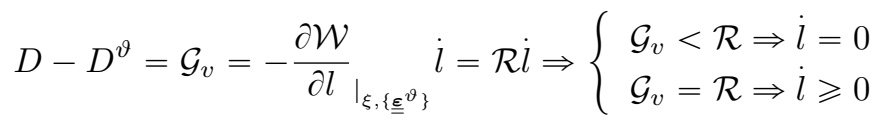


Where $\quad D^{\vartheta}=-\frac{\partial \mathcal{W}}{\partial\left\{\underline{\underline{\varepsilon}}^{v}\right\}}\left\{\dot{\underline{\varepsilon}}^{v}\right\}, \mathcal{G}_{v}$ et $\mathcal{R}$ are respectively viscous dissipation, energy release rate and cracking resistance. A detailed description crack growth modelling can be found in [6].

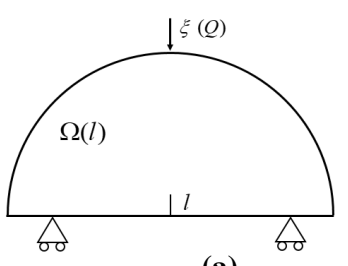

(a)

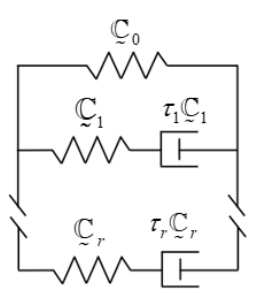

(b)

Fig. 4. (4a) SCB notched geometry ; (4b) GM model

\section{Comparison between numerical model and experiments}

In the framework of numerical simulation, the three-point bending problem is implemented using the finite element library Getfem++[7]. The $\mathcal{R}$ values used in the simulation are summarized in Tab. 1. The results of the computational simulations were validated by comparing them with the experimental results, as shown in Fig. 5a and 5b. In a general way, it can be seen that, for each ageing time and loading rate, the numerical and experimental force - deflexion curves are consistent.

Table 1. Cracking resistance values

\begin{tabular}{ccccc}
\hline $\begin{array}{c}\text { Loading rate } \\
(\mathrm{mm} / \mathrm{min})\end{array}$ & $\begin{array}{c}\mathbf{R} \text { value for t0 } \\
(\mathrm{N} / \mathrm{m})\end{array}$ & $\begin{array}{c}\text { R value for } \mathbf{t 3} \\
(\mathrm{N} / \mathrm{m})\end{array}$ & $\begin{array}{c}\mathbf{R} \text { value for t6 } \\
(\mathrm{N} / \mathrm{m})\end{array}$ & $\begin{array}{c}\mathbf{R} \text { value for t9 } \\
(\mathrm{N} / \mathrm{m})\end{array}$ \\
\hline 1. & 34.43 & 30.34 & 27.04 & 23.12 \\
\hline 5. & 33.92 & 26.49 & 20.53 & 20.29 \\
\hline
\end{tabular}

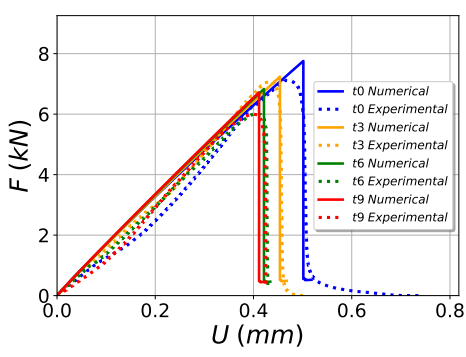

(a)

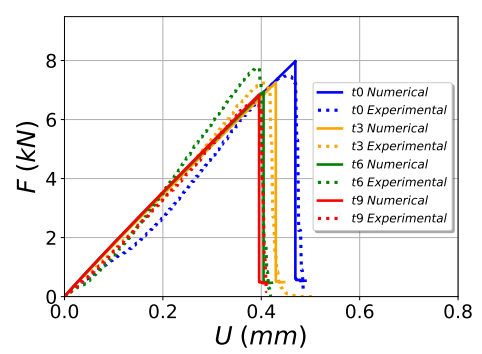

(b)

Fig. 5. Comparison of F_U curves at : (5a) $1 \mathrm{~mm} / \mathrm{min}$; (5b) $5 \mathrm{~mm} / \mathrm{min}$ 


\section{Conclusion}

This study examined the impact of thermal ageing on the mechanical and fracture properties of AC. For this purpose, complex modulus and cracking tests were carried out. Experimental results have shown that thermal ageing increases the stiffness of the material. As a result, the failure deformation decreases when the ageing duration increases. The crack growth modelling approach is then used to simulate semi circular bending problem. Overall, good agreement with experimental results in terms of the force-deflexion curves is obtained for each loading rate and thermal ageing time. This indicates that the model can predict the crack propagation in AC.

Aiming at refining the model, while remaining within reasonable numerical simulation times and further approximating the real material composition (heterogeneity), evolutionary multi-model formulations, articulated within the framework of multi-scale Arlequin models will be conducted and implemented in the future.

\section{References}

[1] Joseph C. Petersen. In A Review of the Fundamentals of Asphalt Oxidation: Chemical, Physicochemical, Physical Property, and Durability Relationships. Transportation Research Board, 2009.

[2] Kim Y R., Castorena C., Elwardany M. D., Rad F. Y., Underwood S., Akshay G., Gudipudi P., Farrar M. J., and Glaser R. R. Long-term aging of asphalt mixtures for performance testing and prediction. Transportation Research Board, 2018.

[3] Barenblatt G.I. The mathematical theory of equilibrium cracks in brittle fracture. volume 7 of Advances in Applied Mechanics, pages 55 - 129. Elsevier, 1962.

[4] Schapery R. A. A. Theory of crak initiation and growth in viscoelastic media. theoretical development. International Journal of Fracture, 11:141-159, 1975.

[5] Nguyen S. T., Dormieux L., Le Pape Y., and Sanahuja J. Crack propagation in viscoelastic structures: Theoretical and numerical analyses. Computational Materials Science, 50(1):83-91, 2010.

[6] Kouevidjin B., Somé C., Barthélémy J-F., Ben Dhia H., and Feeser A. Influence du vieillissement thermique sur les propriétés viscoélastiques et les paramètres de rupture des matériaux bitumineux. In 24e Congrès Français de Mécanique, pages 2689-2698. Brest, France, 2019.

[7] Pommier J. and Renard Y. An open source generic c++ it library for finite element methods. http://getfem.org/. 